\title{
Is Web Based Training Effective on Nursing Skills in Multimodal
}

\section{Analgesia?}

\author{
Kübra Yilmaz ${ }^{1 *}$, Sema Koçaşli and Sevinç Taştan ${ }^{3}$ \\ ${ }^{1} \mathrm{PhD}, \mathrm{RN}$, Research Assistant, Faculty of Health Sciences, Ankara Yildirim Beyazit University, Ankara, Turkey \\ ${ }^{2} R N$, Assistant Professor, Faculty of Health Sciences, Ankara Yildirim Beyazit University, Ankara, Turkey \\ ${ }^{3}$ Prof. Dr., RN, College of Nursing, Girne American University, Girne, Turkish Republic of Northern Cyprus
}

*Corresponding author: Kübra Yilmaz, Research Assistant, PhD, RN, Faculty of Health Sciences, Ankara Yildirim Beyazit University, Ankara, Turkey, Tel: +90-531-680-05-04

\begin{abstract}
Background: The control high prevalence of pain in the world is possible with successful pain management and prevention of pain-related complications. The nurse must have adequate knowledge and skills to be able to manage the pain effectively.

Aim: The purpose of this study is to compare the knowledge, skills, preferred non-pharmacological pain control methods, satisfaction and self-confidence of students who study and control groups.

Materials and methods: Sample size was determined by power analysis. A total of 69 students were randomly assigned to study and control groups. Nursing skills of the study and control groups were evaluated with standard patient simulation in the laboratory environment after the training. In the gathering of data in the study Data Related to Descriptive Characteristics Form, Pre-test, Post-test, and Retention Test, and Skill Test were used. Also, "The Student Satisfaction and Self-Confidence Scale in Learning" and "Web Site Usability Scale" were used.

Results: There was no significant difference between the scores of scales, post-test, and retention test scores between the two groups, but the skill test score of the study group was higher than the control group.

Conclusion: Web-based education positively influenced students' academic achievements and nursing skills. In order to increase the practical skills of nursing students, it is suggested to use web-based education in addition to the classroom presentation technique.
\end{abstract}

\section{Keywords}

Nursing, Education, Web-based learning, Simulation, Multimodal analgesia

\section{Introduction}

Pain is defined as a global health problem with a very high prevalence in the world as a subjective and personal experience involving physical, emotional, and cognitive components [1]. The results of the research done in the literature suggest that $50-70 \%$ of patients have insufficient pain treatment, moderate or severe $[2,3]$. If post-surgical pain is not treated for a long time, it may lead to serious complications it even may become chronic [4].

Guidelines for pain management in our country and in the world to prevent pain, which is an important problem after surgery. Treatment of pain in the direction of recommendations requires a multimodal approach $[5,6]$. Multimodal analgesia is a concept that provides pain management by minimizing the side effects while trying to maximize the effectiveness of analgesics given at optimal doses. In this concept, it is aimed to prevent and treat pain by making use of different mechanisms of analgesics and creating a synergistic effect with analgesics given in combination. The use of multimodal analgesia requires a multidisciplinary team. This team includes many disciplines such as anesthesiologist, nurse, surgeon, pharmacist, physiotherapist. As a result of multidisciplinary rehabilitation, faster recovery and shorter hospital stay can be achieved $[7,8]$. Multimodal analgesia uses non-pharmacological methods as well as pharmacological methods to provide more effective analgesics. This method has a high level of evidence 
for its effectiveness in multimodal analgesic clinical practice guidelines in the management of acute postsurgical pain [9]. Non-pharmacological applications are an important component of multimodal analgesia and have been shown to be effective as part of a perioperative multimodal pain management plan, multimodal analgesic protocol. It also is a concept that plays a key role in the nursing process, which includes pharmacological and non-pharmacological methods that minimize the side effects while trying to remove it. However, the work conducted shows us that, the nurses are inadequate when it comes to evaluation and management of pain, and the reason for this is lack of information [10-12], and this lack of information is possibly due to the nursing education they receive $[12,13]$.

Web-based training which is among the simulation methods is applied by the usage of internet tools and computer support, personal pages prepared to support distance education, and actions that these pages create [14]. Web-based education has advantages such as receive education at the desired place and time, reach the course content according to the learning speed and motivation, quick and easy access to information, to have a rich learning area with text-graphics and video tools, providing interaction between student-student and student-instructor $[15,16]$. There are studies in the literature that determine the effect of web-based education on the academic achievement of nursing students $[17,18]$. Different systems can be used to provide web-based education. One of these systems is for educational purposes. The moodle system is the most widely used, easy to use and supported in 70 languages [19]. In Kuzu's study in which he provided web-based education using the Moodle system, students stated that the ease of use of the Moodle system is an advantage [20]. Moodle is an open source teaching program under MySQL and PostgreSQL database systems that supports PHP software language and can be used in Windows, Linux, Mac OS X operating systems. This system broadcasts via Apache web server and is supported by 150 countries in 70 languages. It can be viewed on all desktop computers, laptops, tablets and smart phones. The reason for choosing the moodle system is that it is the most common corporate-level learning platform with approximately 79 million users in the world, used by many small and large companies and organizations [21].

The standard patient, another simulated method, is a normal person who plays a trained patient role to demonstrate the accurate patient history and examination findings used in practical pieces of training such as interviews and physical examinations before clinical practice is applied to patients clinically [22]. Standard patient use is one of the effective learning methods with the ability to acquire vocational skills for students to develop this professional skill and learning, to solve problems related to skill, to raise awareness about applications, to provide frequent repetition, to provide a safe and risk-free environment [23,24]. This study was carried out to determine the effect of multimodal analgesia approach on post-surgical pain supported by web-based training on the application skills of students on standard patient simulation.

\section{Method}

\section{Type of research}

The research is carried out with an empirical approach in regards to the presentation technique presented to the students concerning the "nursing approach in multimodal analgesia" and to determine whether webbased education has an impact on students' theoretical knowledge and practice skills with pre-test and posttest control groups. The research was conducted in a university in Ankara. In the concerning faculty's nursing department classrooms and the simulation laboratory. It was held in the spring of 2016.

\section{Participants}

The universe of the research is consisted of 140 students who have taken the course of Surgical Diseases Nursing during their graduate study. The sample is calculated as 56 students with a working power of 0.90 . The number of substitute students was calculated as $\% 20$ percent (6 students) and the total number of students was determined as 68 . The study was randomized sampling method and was conducted with 69 students voluntarily participating in the selected research the stands for Consolidated Standards of Reporting (CONSORT) 2015 control list has been taken into consideration concerning the planning and orchestration of the research. There are 34 students in the study group and 35 students in the control group. In both groups, it was taken into consideration that there was no difference between the averages of age, gender, academic achievement grade, whether they had a computer and internet access was taken into consideration. Students who had no active registration in the school and those who were taking the class which was required by the research for a second time and students who didn't volunteer weren't included in the research.

Students who had an active registration at the university, chose the course of surgical diseases nursing, and volunteered to participate in the research were included in the study. Students who did not have an active registration at the university, did not choose this course, did not want to participate in the research and took this course before were excluded from the research. Before the written consent of the students was obtained, they were informed that purpose of research. The research would not affect their grades, that they could withdraw from the research at any time, that they were not charged or paid. The students were 
informed that participation in the research would not affect their exam grade, they could withdraw from the study whenever they wanted and they would not be paid.

The students participating in the study were randomly divided into study and control groups. There was no statistical difference between the age, gender and general average grade of the students in both groups.

\section{Data collection tools}

In the gathering of data in the study "Data Related to Descriptive Characteristics Form", "Web Site Usability Scale", "Learned Student Satisfaction and SelfConfidence Scale", "Pre-test, Post-test, and Retention test" and "Skill Test" were used. "Data Related to Descriptive Characteristics Form" was developed by the researcher and consists of 3 parts. Part 1 is a 13-question part with sociodemographic data. Part 2 is the part where students are asked to evaluate their knowledge and skills about nursing approach in postoperative pain and multimodal analgesia with the answers such as "adequate, partially sufficient, insufficient". This section consists of six questions. Part 3 is a five-question section in which students' self-study habits are asked to be evaluated by the student, computer and internet usage possibilities, the purposes of using the internet, and the effect of web-based education on nursing knowledge and skills in post-surgical pain.

"Website usability scale"; Kiliç Çakmak, et al. developed it, conducted validity and reliability studies, and as a result determined it as a scale that could be applied in our country [25]. It is a 25-question scale that includes ease of navigation, design, ease of access, and ease of use. Each statement in the scale was evaluated over five options and was scored as "Strongly agree (5)", "Agree (4)", "Undecided (3)", "Disagree (2)", "Strongly Disagree (1)". Only four questions in the ease of use part are reversed and this part is scored as "Strongly disagree (5)", "Disagree (4)", "Undecided (3)", "Agree (2)", "Strongly agree (1)". The lowest 25 and the highest 125 points can be obtained from the scale. The high score obtained from the scale indicates that the usability of the website is high. In our study, the Cronbach Alpha internal consistency coefficient was 0.90 for the "Ease of Navigation" factor, 0.88 for the "Design" factor, 0.76 for the "Ease of Access" factor, 0.85 for the "Ease of Use" factor, and the Cronbach Alpha internal consistency coefficient calculated for the whole scale was 0.93.

The Turkish validity and reliability of the "Student Satisfaction and Self-Confidence in Learning Scale", developed by the National League of Nursing in 2013, was made by Unver, et al. the scale is a 12-question scale consisting of two parts, "satisfaction with current learning" and "self-confidence in learning". In the evaluation of the scale, each statement was scored over 5 options [26]. These; "Strongly agree (5)", "Agree (4)", "Undecided (3)", "Disagree (2)", "Strongly disagree (1)". The score calculation is calculated by taking the average of the selected scores. The higher the average, the higher the student's satisfaction and self-confidence in learning. In our study, the Cronbach's alpha internal consistency coefficient of the scale was 0.79 , and the Cronbach's alpha internal consistency coefficient of self-confidence was 0.74 .

The "Successful Test" was structured in four stages by the researcher by scanning the relevant literature. A multiple-choice achievement test with 59 questions was created on the subject, arrangements of the achievement test were made by taking expert opinion on the content from three faculty members, two of whom were experts in the field of medicine, and a total of 21 students were pre-applied in terms of item analysis, achievement test according to the results of item analysis. It was rearranged and took its final form as a 20-question multiple-choice achievement test. Students can get the lowest 0 points and the highest 100 points from this test.

In the study, a skill checklist was prepared by the researcher in line with the literature in order to determine the effect of web-based training on the psychomotor skill levels of the multimodal nursing approach in postoperative pain in addition to the education provided by the presentation method of the students. This "Skill test" consists of 25 items for which the relevant items are evaluated as "applied", "partially applied" and "not applied".

\section{Implementation steps of the preparation study}

Preparing the success test: It was determined using the "Chi-square goodness of fit test". In order to calculate the number of sampling required for the study. Success test was applied to 21 students and item strength and discriminant index were calculated. 20 questions were selected from the pool of 59 questions created.

Creation of training content: While preparing the training content, the "International Association for the Study of Pain (IASP)" for the nurses and current guidelines for the ERAS protocols were taken into consideration. We have also taken the views of 3 faculty members specializing in the field.

Preparation of web-based training: Moodle system was preferred for web-based training and the user name and password were given to the students in cooperation with the remote education center of the university and the training content was uploaded to the system.

Preparation of simulation environment and scenario: The simulation scenario is based on the views of two specializing faculty members and accordingly to the standards developed by The International Nursing Association for Clinical Simulation and Learning 
(INACSL), which are the "Standards of Best Practice: Simulation 2013" and to the Objective Structured Clinical Assessment (OSCA).

Preparation of the observer: Two observers were selected for the study. While the observers were being chosen, the similarity of their level of education, job experience and age was taken into account. Information on the purpose of the study, its scope, its importance, learning outcomes were given, afterward, information about the simulation scenario and skill checklist steps were given and responsibilities were explained. The observers were not informed about which group the students they observed belonged to.

\section{Implementation of the research}

The students participating in the research were divided into two groups as study and control groups. The successful test was applied simultaneously to the study and control groups in the classroom environment before the training was given. "Nursing Approaches in Multimodal Analgesia" training was given to the study and control groups at the designated time and in the classroom with the help of computer and projection. At the end of the presentation method, after the study group was taken to a different class. After the presentation method, the study group was given the username and password that they can enter into the web-based training system. The final achievement test was applied to the groups in the classroom environment. The forms were filled under the supervision of the researcher in order to prevent the interaction between the students. In addition, a confidentiality agreement was signed with the students while obtaining their written consent to participate in the research.

The simulation scenario is based on the views of two specializing faculty members and accordingly to the standards developed by the International Nursing Association for Clinical Simulation and Learning (INACSL), which are the "Standards of Best Practice: Simulation 2013" and to the Objective Structured Clinical Assessment (OSCA). Two observers were selected for the study. The prepared simulation scenario was applied with the standard patient in the environment prepared for the scenario on the date and time determined by the students in advance. Five minutes for pre-briefing, 15 minutes for administration and 30 minutes for evaluation were allocated to each group. The application was recorded with a camera and camera recordings were used in the evaluation.

After the debriefing phase of the simulation application, the students were given scales and asked to fill it. Retention is assessed by tests administered two weeks or more after training or instruction is given. Although the duration of the retention tests in recent studies usually intensifies between 1-6 weeks, the application of the permanence test in education in the field of health practices after two weeks increases the consistency of the tests [21,22]. Therefore, two weeks after the presentation method, a retention test was applied to the control group, and two weeks after the access to web-based education was closed to the study group.

\section{The ethical dimension of the study}

For the research, necessary written permits have been obtained from the XXX ethics committee (approval number: 256), faculty dean and the head of the nursing department. The students who participated in the research were informed about the research and written and verbal permission was obtained from the volunteers.

\section{Statistical analysis}

For statistical analysis and calculations, IBM SPSS Statistics 21.0 released 2012, IBM SPSS Statistics for Windows, Version 21.0. Armonk, NY: IBM Corp.) and MS-Excel 2007 programs were used. In the analysis of the study, number, percentage, Shapiro Wilks, T-test, Fisher Ki Square, Yates Continuity, Likelihood Ki Square, Cronbach Alpha, Mann Whitney U, Friedman, Rho Correlation, Wilcoxon $\mathrm{W}$ and Ancova tests were used.

\section{Result}

The average age of the students in the study and control group is $20.6 \pm 1.0$ and $20.5 \pm 1.0$ years, respectively (Table 1 ). When the descriptive characteristics of the students are examined, there was no statistically significant difference between the academic achievement grade points average $(p>0.05)$.

When the two groups were compared, the number of students who had their own computer in the study group was higher than the control group and a statistically significant difference was found. ( $p=0.023)$. The view on adequacy on theoretical knowledge and clinical competence concerning pain and multimodal analgesia, self-study habits, internet access and internet usage purposes, web based education and free-will based choice of the nursing department were found to be similar on both groups $(p>0.05)$.

When the pre-test, post-test, and retention test scores of the two groups were compared, the pre-test success score of the control group was higher and there was no significant difference between the post-test and retention scores $(p<0.01, p=0.083, p=0.776)$, to sterilize the effect of pre-test score difference concerning the research, percent change and covariance analysis were performed. According to the results of covariance analysis and success rate test results' change results' means there was no statistically significant difference between the two groups $(p>0.05)$ between the last test and retention test success scores (Table 2 and Figure 1 ).

When the skill scores of the two groups were 
Table 1: Data on the descriptive characteristics of the students.

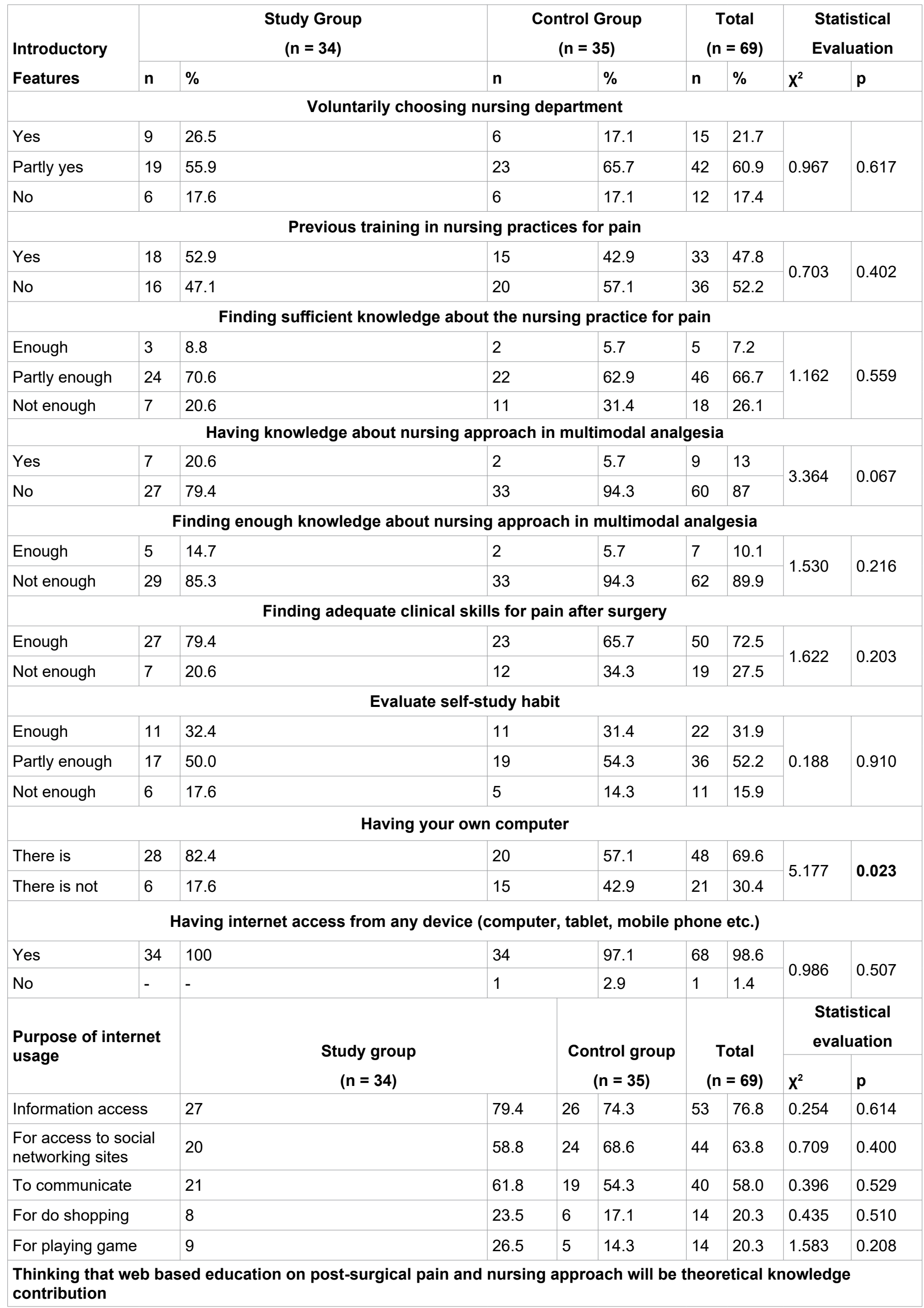




\begin{tabular}{|l|l|l|l|l|l|l|l|l|}
\hline Yes & 26 & 76.5 & 25 & 71.4 & 51 & 73.9 & & \\
\hline Partly yes & 8 & 23.5 & 8 & 22.9 & 16 & 23.2 & 2.006 & 0.367 \\
\hline No & 0 & 0 & 2 & 5.7 & 2 & 2.9 & \\
\hline
\end{tabular}

Thinking that web based education about pain and nursing approach after surgery will be a clinical skill contribution

\begin{tabular}{|l|l|l|l|l|l|l|l|l|}
\hline Yes & 28 & 76.5 & 23 & 65.7 & 49 & 71.0 & & \\
\hline Partly yes & 8 & 23.5 & 11 & 31.4 & 19 & 27.5 & 1.643 & 0.440 \\
\hline No & 0 & 0 & 1 & 2.9 & 1 & 1.4 & \\
\hline
\end{tabular}

Students' overall grade point average

Statistical

evaluation

\section{Study Group}

Average

$\min ; \max$

Mean \pm SD

$2.77 \pm 0.43$

$1.40 ; 3.54$

\begin{tabular}{|l|l|l|}
\hline Control Group & t & p \\
\hline $\begin{array}{l}\text { Average } \\
\text { min; max } \\
\text { Mean } \pm \text { SD }\end{array}$ & 0.161 & 0.873 \\
$2.78 \pm 0.392 .05 ; 3.56$ & & \\
\hline
\end{tabular}

Table 2: Comparison of achievement test scores of students $(N=69)$.

\begin{tabular}{|c|c|c|c|c|c|c|c|}
\hline \multirow{2}{*}{\multicolumn{2}{|c|}{$\begin{array}{l}\text { Comparison of Success Test } \\
\text { Scores and Scale Scores }\end{array}$}} & \multicolumn{2}{|c|}{$\begin{array}{l}\text { Study Group } \\
\qquad(\mathrm{N}=34)\end{array}$} & \multicolumn{2}{|c|}{$\begin{array}{l}\text { Control Group } \\
\qquad(\mathbf{N}=35)\end{array}$} & \multicolumn{2}{|c|}{$\begin{array}{l}\text { Statistical } \\
\text { Evaluation }\end{array}$} \\
\hline & & $\begin{array}{l}\text { Hydrangea } \\
\text { Min; Maks }\end{array}$ & Mean \pm SD & $\begin{array}{l}\text { Hydrangea } \\
\text { Min; Maks }\end{array}$ & Mean \pm SD & $\mathbf{Z}$ & $\mathbf{p}$ \\
\hline \multicolumn{8}{|c|}{ Successful Test } \\
\hline \multicolumn{2}{|l|}{ Pre Test } & $\begin{array}{l}25^{\mathrm{A}, \mathrm{B}} \\
15 ; 45\end{array}$ & $26.8 \pm 7.7$ & $\begin{array}{l}35^{\mathrm{A}, \mathrm{B}} \\
20 ; 55\end{array}$ & $34.6 \pm 9.4$ & 3.375 & $<0.001$ \\
\hline \multicolumn{2}{|l|}{ Post Test } & $\begin{array}{l}62.5^{\mathrm{A}} \\
30 ; 80\end{array}$ & $58.8 \pm 14.9$ & $\begin{array}{l}70^{A} \\
20 ; 100\end{array}$ & $65.1 \pm 17.6$ & 1.734 & 0.083 \\
\hline \multicolumn{2}{|l|}{ Retention Test } & $\begin{array}{l}67.5^{B} \\
20 ; 80\end{array}$ & $61.5 \pm 15.9$ & $\begin{array}{l}65^{\mathrm{B}} \\
30 ; 85\end{array}$ & $63.3 \pm 13.7$ & 0.285 & 0.776 \\
\hline \multicolumn{2}{|c|}{ Statistical Evaluation } & \multicolumn{2}{|c|}{$X^{2}=47.145 ; P<0.001$} & \multicolumn{4}{|c|}{$X^{2}=42.493 ; P<0.001$} \\
\hline \multicolumn{2}{|c|}{ Covariance of Post Test Score } & Sum Of Squares & Df & Mean Square & $\begin{array}{l}\text { F } \\
\text { (Anova) }\end{array}$ & $\mathrm{p}$ & \\
\hline \multicolumn{2}{|l|}{ Total } & 284000 & 69 & & & & \\
\hline \multicolumn{2}{|c|}{ Pretest Total Score } & 36.8 & 1 & 36.8 & 2.581 & 0.713 & \\
\hline \multicolumn{2}{|l|}{ Intergroups } & 695.7 & 1 & 695.7 & 0.136 & 0.113 & \\
\hline \multicolumn{2}{|c|}{$\begin{array}{l}\text { Covariance of Retention Test } \\
\text { Score }\end{array}$} & Sum Of Squares & Df & Mean Square & $\begin{array}{l}\text { F } \\
\text { (Anova) }\end{array}$ & $P$ & \\
\hline \multicolumn{2}{|l|}{ Total } & 283375 & 69 & & & & \\
\hline \multicolumn{2}{|c|}{ Pretest Total Score } & 75.2 & 1 & 75.2 & 0.339 & 0.562 & \\
\hline \multicolumn{2}{|c|}{ Intergroups } & 10.4 & 1 & 10.4 & 0.047 & 0.829 & \\
\hline \multirow{2}{*}{$\begin{array}{l}\text { Changes of } \\
\text { skill Points of } \\
\text { Students }\end{array}$} & \multicolumn{2}{|c|}{ Study Group } & \multicolumn{2}{|c|}{ Control Group } & \multicolumn{3}{|c|}{ Statistical Evaluation } \\
\hline & $\begin{array}{l}\text { Hydrangea } \\
\text { Min; Maks }\end{array}$ & Mean \pm SD & $\begin{array}{l}\text { Hydrangea } \\
\text { Min; Maks }\end{array}$ & Mean \pm SD & Z & $p$ & \\
\hline Skill Score & $\begin{array}{l}80.0 \\
76 ; 92\end{array}$ & $82.9 \pm 6.4$ & $\begin{array}{l}68.0 \\
36 ; 84\end{array}$ & $66.9 \pm 15.4$ & 2.169 & 0.038 & \\
\hline
\end{tabular}




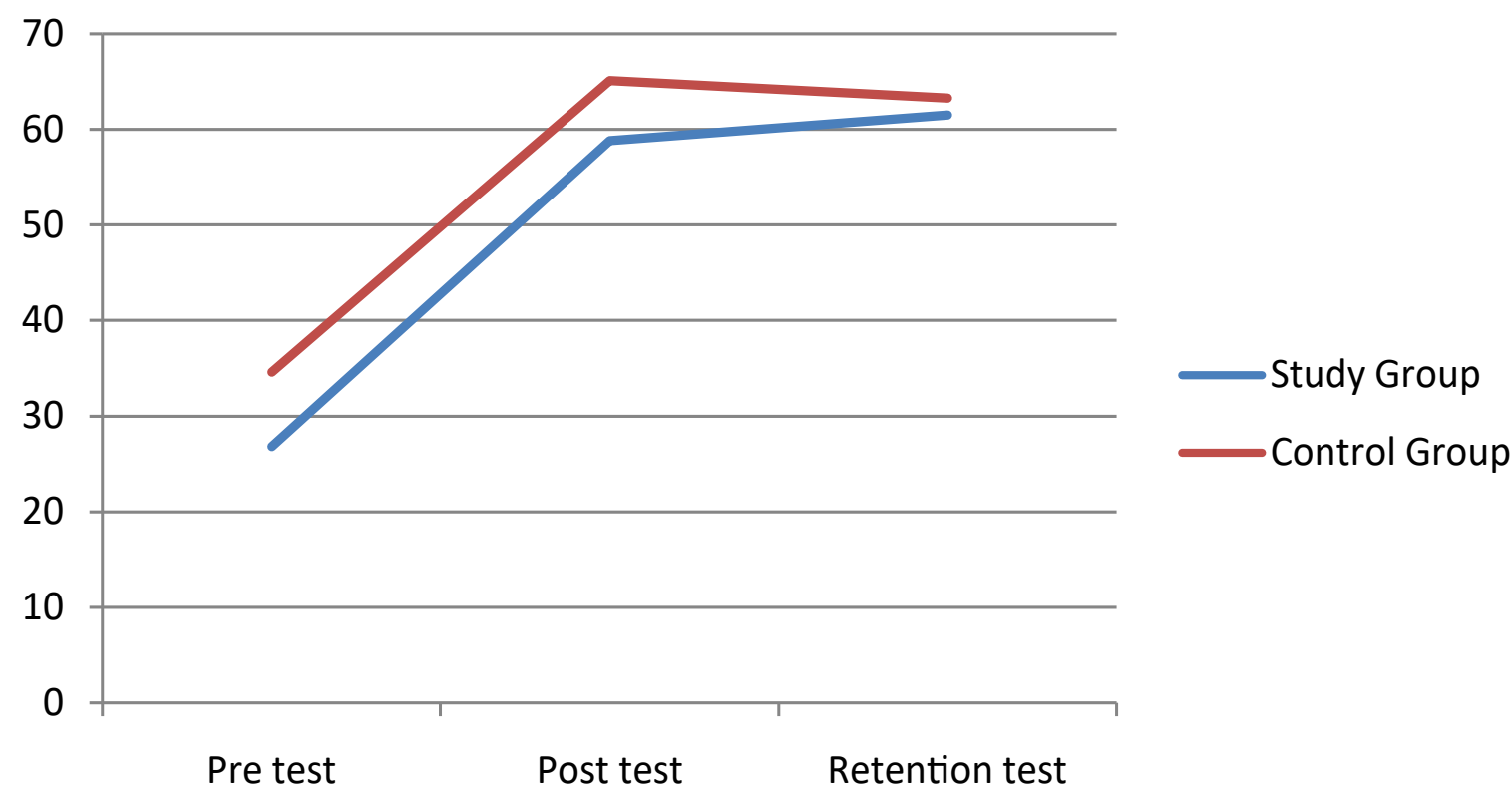

Figure 1: Mean of success test score.

Table 3: Relationship between students' scores of post-test, student satisfaction and self confidence on learning scale scores and skill test.

\begin{tabular}{|l|l|l|l|l|}
\hline \multirow{2}{*}{} & \multicolumn{3}{|c|}{ Skill Score } \\
\cline { 2 - 5 } & \multicolumn{2}{|c|}{ Study Group } & \multicolumn{2}{c|}{ Control Group } \\
\hline Post test & rho & $\mathrm{p}$ & rho & $\mathrm{p}$ \\
\hline Satisfaction & -0.170 & 0.716 & 0.563 & 0.188 \\
\hline Self-confidence & -0.547 & 0.204 & -0.112 & 0.812 \\
\hline
\end{tabular}

Table 4: Non-pharmacological methods used by students.

\begin{tabular}{|l|l|l|}
\hline Non-pharmacological methods used by groups & Working Group & Control Group \\
\hline Position & 4 group & 6 group \\
\hline Breathing exercise & 3 group & 4 group \\
\hline Massage & - & 1 group \\
\hline Distract & 4 group & 1 group \\
\hline Relaxation exercise & - & 1 group \\
\hline Cold therapy & 6 group & 5 group \\
\hline Mobilization & 4 group & 1 group \\
\hline Encouraging sleep-rest & 1 group & - \\
\hline
\end{tabular}

compared, the skill score of the study group was higher than that of the control group, and a statistically significant difference was found $(p=0.038)$. While both groups were assessing their application skills during the standard patient simulation, student satisfaction, and self-confidence in learning to determine their effect on their skills scale was applied.

The Cronbach's alpha coefficient of the Web Site Usability Scale used in our study was 0.93 , the mean score was $111.4 \pm 12.7$ and the system was accessed 117 times. The satisfaction subscale of student satisfaction and self-confidence on learning Cronbach alpha fold was 0.79 and self-confidence was 0.74 . The scales used were appropriate for the study population and there was no significant difference between satisfaction and self-confidence subscales. $(p=0.71, p=0.29)$. This removed the differences from the simulation practice, removing the effect on the skill assessment. Skill scores of the students were compared with the sub-dimensions of post-test, satisfaction, and self-confidence, but no significant difference was found $(p<0.05)$ (Table 3 ).

There are nonpharmacologic methods for pain in a place that students use during the simulation. As the number of subjects in the cells was insufficient, the difference between the two groups was not compared, however, while the control group used the positioning, 
breathing exercise and cold application methods more, the study group used the methods of the positioning, breathing exercise, cold application, drawing attention and mobilization (Table 4).

\section{Discussion}

In our study, we applied the "Website Usability Scale to the study group in order to evaluate the moodle system. As a result of the research, the scale scores were found high. As a result of Kuzu and Balamir's study, students found the moodle system easy to use [27].

There are studies in the literature that provide nursing students with web-based learning and analyze the results. Deloian, et al. provided web-based breastfeeding training to a total of 7570 nurses, nursing students, and nurse practitioners. As a result, when the pretest and post-test scores were compared, an increase in knowledge levels was found [28]. Study of Pishgooie, et al. divided the nursing students into two groups in their studies. They gave web-based learning to the study group and lecture to the control group. As a result of the research, a significant increase was found in the post test and retention tests of the study group [29]. The results of our study, although the pretest scores of the students in the study group were lower than the successful scores of the students in the control group, after the web-based education, the study group's post-test and retention test success scores were similar to the control group. When the effect of webbased education on nursing practice skills, the skill score of the study group was higher than the control group ( $p$ $<0.05)$.

In study of Park, et al. applied web-based experiential learning to the study group and provided training to the control group with written material. The groups consisted of undergraduate nursing students. As a result of the research, the knowledge, skill, attitude and practice scores did not differ significantly between the two groups [30]. In the study of Steinke, et al., nursing students were given web-based training including webbased education and blood-based socio-cognitive sexual counseling for patients with cardiovascular problems. As a result of the research, it was found that the level of ability of students to give sexual counseling increased $[31,32]$. In these studies, web-based learning increased students' skill levels as well as their knowledge levels. In our study, the skill score of the study group was higher than the control group, and this difference was statistically significant $(p<0.05)$.

The study conducted by Ozturk and Dinç in our country, training on nursing students regarding the application of urinary catheters, web-based training for the study group, and traditional training for the control group were given via traditional education. There was no significant difference in achievement scores between the two groups, and the score of the skill was higher in the study group our study [16]. The results of our study are particularly similar to this study. In both studies, while knowledge levels did not differ significantly between the two groups, skill levels showed a significant difference.

Research in the literature and the results of our research have shown that web-based education positively affects nursing education. When dealing with web-based learning, we should consider that nursing education consists of theory and practice. Transferring knowledge of nursing students to practice and developing application skills are important in terms of preventing incomplete and incorrect applications. However, the number of nurse educators and laboratories is low, the clinical education areas are inadequate and the number of students is high, negatively affecting students' nursing practice skills. It is believed that the combination of student face-to-face and web-based training positively affects the skills of students. Visual rich content used in web-based education helps mental revitalization, embodies concepts and keeps attention alive [33]. Due to these advantages web-based education is thought to increase the knowledge and skills of nursing students.

In our study, we used standard patient simulation to evaluate the skills of nursing students who were given web-based education. We chose standard patient simulation to create a safe environment for students and patients, to better focus the student and to evaluate postoperative pain. Meta analysis of Kim, et al. reported that one of the simulation methods with the greatest effect size among the emotional results is the standard patient simulation [30]. In study of Ham, found that the use of standard patients improved the communication skills and safe nursing care practices of nursing students, while Sarsamoğlu, et al. found that the standard patient simulation improved the psychomotor skills of nursing students [34,35]. Yong-Shian, et al. found that standard patient simulation increased the satisfaction and selfconfidence of the nursing students [36]. Studies in the literature have shown that standard patient simulation contributes positively to students' practice and psychomotor skills. While evaluating the effectiveness of standard patient simulation, we used "Student Satisfaction and Self-Confidence Scale in Learning". Our research results have been in line with the literature. Students' self-confidence and satisfaction scores were high.

As a result, it was determined in our study that standard patient simulation is an effective method in assessment of skills in nursing education and increases student's satisfaction and self-confidence level. In addition, moodle system is a useful system for webbased education and web-based education is effective in increasing knowledge and skills of nursing students.

\section{Limitation}

Conducting the research at a university may be a 
limitation of the research. The research results require new research that also investigates the causality aspect. The widespread use of the internet may have had a positive effect on the use of web-based education in nursing students, and may have positively affected the scores of the usability scale for the moodle system.

\section{Conclusion}

The results obtained from this study reveal that nursing students improve their post-surgical pain management skills when web-based training is given together with the training given by the presentation technique. For this reason, school administrators and educators should make the necessary arrangements for the implementation of web-based education in schools, the face-to-face education and support of nursing practice skills, and this should be taken into account in the revision of course contents. In the direction with the results of this research, dissemination of Web-based education in schools, in subjects that require the ability of nursing application, should be installed as support and additionality to face-to-face training.

In the direction with the results of this research, which found that web based education given in addition to face-to-face training in nursing education positively affects students' abilities; to provide the necessary technical support and infrastructure for nursing education in computer and internet usage, and if there is a web based nursing education in the university, a multidisciplinary team work concerning the distanceeducation center and relevant engineering departments is suggested.

\section{Authors' Contributions}

Study conception and design: KY, SK, ST. Data collection: KY. Data analysis and interpretation: KY, SK, ST. Drafting of the article: KY.

\section{Conflicts of Interest}

This manuscript has not been published elsewhere. All authors have approved the manuscript and agree with submission. The authors have not conflicts of declare of interest.

\section{Funding}

None.

\section{Acknowledgments}

None.

\section{Supplementary Materials}

None.

\section{References}

1. Goldberg DS, McGee SJ (2011) Pain as a global public health priority. BMC Public Health 11: 770.

2. Tong JG (2017) Poorly controlled postoperative pain:
Prevalence, consequences, and prevention. J Pain Res 10: 2287-2298.

3. Meissner W, Coluzzi F, Fletcher D, Huygen F, Morlion B, et al. (2015) Improving the management of post-operative acute pain: Priorities for change. Curr Med Res Opin 31: 2131-2143.

4. Glare P, Aubrey KR, Myles PS (2019) Transition from acute to chronic pain after surgery. Lancet 393: 1537-1546.

5. Simpson JC, Bao X, Agarwala A (2019) Pain management in enhanced recovery after surgery (ERAS) protocols. Clin Colon Rectal Surg 32: 121-128.

6. Polomano RC, Fillman M, Giordano NA, Vallerand $A H$, Nicely KLW, et al. (2017) Multimodal analgesia for acute postoperative and trauma-related pain. Am J Nurs 117: S12-S26.

7. Gajraj NM, Joshi GP (2005) Role of cyclooxygenase-2 inhibitors in postoperative pain management. Anesthesiol Clin North Am 25: 49-72.

8. Sivrikaya GU (2012) Multimodal analgesia for postoperative pain management. In: Racz G, Pain Management - Current Issues and Opinions. InTech, Rijeka, Croatia.

9. Manworren RCB (2015) Multimodal pain management and the future of a personalized medicine approach to pain. AORN J 101: 308-314.

10. Chow KM, Chan JCY (2015) Pain knowledge and attitudes of nursing students: A literature review. Nurse Educ Today 35: $366-372$

11. Mackintosh-Franklin C (2017) Pain: A content review of undergraduate pre-registration nurse education in the United Kingdom. Nurse Educ Today 48: 84-89.

12. Dirimeşe E, Kardaş Özdemir F, Akgün Şahin Z (2016) Nursing students' knowledge of related to pain management, cultural awareness and competence. Gümüşhane University Journal of Health Sciences 5: 1-6.

13. Germossa GN, Sjetne IS, Hellesø R (2018) The impact of an in-service educational program on nurses' knowledge and attitudes regarding pain management in an Ethiopian University Hospital. Front Public Health 6: 229.

14. Tektaş $M$ (2010) Web based artificial intelligence techniques training simulation preparation. Marmara University, Scientific Research Projects Commission, 20-24.

15. Purnell L, Rastinehad D, Nettleton B (2012) Getting started with web-based learning in nursing: The essentials. Deuhyo Ed 5: 23-27.

16. Öztürk D, Dinc L (2014) Effect of web-based education on nursing students urinary catheterization knowledge and skills. Nurse Educ Today 34: 802-808.

17. Cooke M, Watson B, Blacklock E, Mansah M, Howard M, et al. (2012) Lecture Capture: First year student nurses' experiences of a web based lecture technology. Australian Journal of Advanced Nursing 29: 14-21.

18. Gerdprasert S, Pruksacheva T, Panijpan B, Ruenwongsa $P(2011)$ An interactive web-based learning unit to facilitate and improve intrapartum nursing care of nursing students. Nurse Educ Today 31: 531-535.

19. Moodle (2016) About Moodle.

20. Al-Ajlan A, Zedan $H(2008)$ Why moodle. In: $12^{\text {th }}$ IEEE International Workshop on Future Trends of Distributed Computing Systems. IEEE, 58-64.

21. Kuzu S, Balaman F (2014) Moodle kullanilarak 
gerçekleştirilen web destekli eğitim hakkindaki öğrenci görüşleri. Eğitim ve Öğretim Araştirmalari Dergisi 3: 234242.

22. Terzioğlu F, Kapucu S, Özdemir L, Boztepe H, Duygulu S (2012) Nursing students' opinions about simulation method. Hacettepe University Faculty of Health Sciences Nursing Journal, 16-23.

23. Erkalp K, Çokay Abut FY, Kitapçioğlu D, Aşik Eren G, Aksoy ME (2013) Simulation education of anaesthesiology and reanimation residents: A four-year Simmerk ${ }^{\circledR}$ experience. GKDA Journal 19: 23-30.

24. Beigzadeh A, Bahmanbijri B, Sharifpoor E, Rahimi M (2016) Standardized patients versus simulated patients in medical education: Are they the same or different. Journal of Emergency Practice and Trauma 2: 25-28.

25. Kiliç Çakmak E, Güneş E, Tahsin M (2011) Development of website usability scale: Validity, reliability analysis and application results. Pegem Education and Training Journal 1: $31-40$.

26. Unver V, Başak T, Watts P, Gaioso V, Moss J, et al. (2017) The reliability and validity of the three questionnaires: The student satisfaction and self confidence in learning scale, simulation design scale and educational practices questionnaire. Contemp Nurse 53: 60-74.

27. Kuzu S, Balaman F (2014) Student views upon the web based education by using Moodle. Journal of Research in Education and Teaching 3: 234-242.

28. Deloian BJ, Lewin LO, O'Connor ME (2015) Use of a webbased education program improves nurses' knowledge of breastfeeding. J Obstet Gynecol Neonatal Nurs 44: 77-86.
29. Pishgooie AH, Aliyari $S$, Baniyaghoobi $F$, Sharififar $S$, Dadgari A (2019) The comparison of lecture-based and web-based education on nursing students' learning in the management of radiation injuries. Health in Emergencies \& Disasters Quarterly 4: 71-78.

30. Park M, Jeong M, Lee M, Cullen L (2020) Web-based experiential learning strategies to enhance the evidencebased-practice competence of undergraduate nursing students. Nurse Educ Today 91: 104466.

31. Steinke EE, Barnason S, Mosack V, Hill TJ (2016) Baccalaureate nursing students' application of socialcognitive sexual counseling for cardiovascular patients: A web-based educational intervention. Nurse Education Today 44: 43-50.

32. Kromann CB, Jensen ML, Ringsted C (2009) The effect of testing on skills learning. Med Educ 43: 21-27.

33. Kim J, Park JH, Shin S (2016) Effectiveness of simulationbased nursing education depending on fidelity: A metaanalysis. BMC Med Educ 16: 152.

34. Ham KL (2016) Use of standardized patients to enhance simulation of medication administration. Nurse Educ 41: 166-168.

35. Sarmasoglu S, Dinç L, Elçin M (2016) Using standardized patients in nursing education: Effects on students' psychomotor skill development. Nurse Educ 41: E1-E5.

36. Goh YS, Selvarajan S, Chng ML, Tan CS, Yobas P (2016) Using standardized patients in enhancing undergraduate students' learning experience in mental health nursing. Nurse Educ Today 45: 167-172. 